\title{
Tinjauan Ulang Potensi Sense of place dalam Pelestarian Kawasan Pusaka Perkotaan
}

\author{
Re-Thinking the Potensial of Sense of place in Urban Heritage \\ Conservation
}

\section{Christin Dameria ${ }^{1}$, Roos Akbar ${ }^{2}$, Petrus Natalivan Indradjati², dan Dewi Sawitri Tjokropandojo ${ }^{3}$}

\begin{abstract}
Abstrak: Perencanaan pelestarian kawasan pusaka di perkotaan berupaya menghasilkan pengalaman ruang berkarakter sejarah untuk menghadirkan sense of place yaitu suatu ikatan yang terjalin antara manusia dengan tempat. Namun perencanaan yang berfokus pada sense of place justru dikritik karena dianggap terjebak pada penciptaan-tempat semata dan mengabaikan dimensi manusia. Kajian mengenai potensi sense of place dalam pelestarian kawasan pusaka perkotaan memang masih terbatas padahal potensi ini perlu dikaji lebih lanjut karena kawasan pusaka perkotaan memiliki signifikansi budaya yang patut dilestarikan dengan melibatkan manusia. Tulisan ini merupakan kajian literatur yang mengeksplorasi potensi sense of place terkait dimensi manusia yang dapat dimanfaatkan untuk keberhasilan pelestarian kawasan pusaka perkotaan. Dalam pelestarian kawasan pusaka perkotaan, selain bermanfaat untuk penciptaan-tempat, ditemukan bahwa sense of place juga berpotensi sebagai, informasi panduan dalam perencanaan ruang kawasan pusaka perkotaan, faktor yang memengaruhi partisipasi keterlibatan warga lokal dalam perencanaan kawasan pusaka perkotaan serta faktor yang berhubungan dengan perilaku melestarikan pusaka.
\end{abstract}

Kata kunci: pelestarian, pusaka, sense of place, perkotaan

\begin{abstract}
Urban heritage conservation planning seeks to produce place experience with historical characteristics to bring sense of place that is a relation between human and place. However heritage urban planning that focuses on the sense of place actually gets criticized for being stuck in place-making purposes only and ignores the human dimension. The study of the sense of place potential in the urban heritage conservation is indeed still limited even though this potential needs to be studied futher because urban heritage place have cultural significant values which should be conserved by involving human dimensions. This paper is a literature review that intends to explore others sense of place potential related to human dimensions that can be used to successfully urban heritage conservation. In urban heritage conservation, besides being beneficial for place-making, it was found that the sense of place also has the potential as guidance information in the urban heritage spatial planning, factors that influence the participation of local residents to be involved in urban heritage planning, and factors related to heritage conserving behavior.
\end{abstract}

Keywords: conservation, heritage, sense of place, urban

\footnotetext{
${ }^{1}$ Program Doktor Perencanaan Wilayah dan Kota Institut Teknologi Bandung

${ }^{2}$ Kelompok Keahlian Perencanaan dan Perancangan Kota Institut Teknologi Bandung

${ }^{3}$ Kelompok Keahlian Perencanaan Wilayah dan Perdesaan Institut Teknologi Bandung
} 


\section{PENDAHULUAN}

Saat ini, literatur akademik telah mulai banyak membicarakan hubungan kawasan pusaka yang bernilai sejarah dengan kehadiran sense of place. Kawasan pusaka merupakan kombinasi dari tempat yang bersignifikansi budaya dan memiliki nilai-nilai pusaka (Australia ICOMOS, 2013; Litvin dalam Harper dkk., 2015). Nilai-nilai signifikansi budaya tersebut adalah nilai sejarah, estetika, sosial, dan pendidikan di kawasan pusaka yang harus dijaga agar dapat diwariskan untuk generasi masa depan (Australia ICOMOS, 2013). Kata "tempat" dalam kalimat sebelumnya serta dalam pernyataan-pernyataan berikutnya dalam tulisan ini, sebenarnya merupakan penerjemahan istilah "place" yaitu ruang, yang tidak hanya merujuk pada lokasi geografi, tetapi juga yang telah diberikan makna oleh manusia yang beraktivitas di dalamnya (Graham \& Healey, 1999; Williams, 2014). Tempat-tempat yang bernilai pusaka itu disebut Rodwell (2003) sebagai tempat dengan jiwa - a genius loci, yang memiliki identitas, pencapaian budaya, serta menjadi lokasi manusia berevolusi dari waktu ke waktu. Hubungan kawasan pusaka dengan sense of place dijelaskan English Heritage (2009) melalui pernyataan: "Lingkungan bersejarah berhubungan positif dengan cara orang-orang merasakan tempat di mana mereka tinggal, atau dengan kata lain, dengan sense of place yang mereka miliki".

Adanya pemahaman bahwa kawasan bersejarah berelasi signifikan dengan sense of place mendorong hadirnya pendekatan pelestarian yang berfokus pada keberadaan sense of place. Muncul kemudian gagasan perlunya menghadirkan, memperkuat, dan menghargai sense of place dalam konsep perencanaan kawasan pusaka di perkotaan (Ouf, 2001; Nasser, 2003; Martokusumo, 2011). Bentuk pendekatan pelestarian ini sebenarnya merupakan sebuah kritik terhadap pendekatan sebelumnya yang dianggap lebih memerhatikan keberadaan bangunan tunggal. Pendekatan pelestarian kawasan pusaka di perkotaan masih lebih berfokus pada isu-isu keaslian daripada melestarikan pengalaman perkotaan padahal upaya pelestarian seharusnya juga mampu menghadirkan sense of place daripada sekadar merestorasi detail (Ouf, 2001; Martokusumo, 2015).

Meskipun sense of place telah mulai diperhatikan dalam perkembangan pendekatan pelestarian kawasan pusaka di perkotaan, namun aplikasi konsep ini dalam pelestarian itu sendiri masih mengundang perdebatan. Di satu pihak, Ouf (2001) berpendapat bahwa penciptaan sense of place itu tidaklah rumit karena para perencana atau perancang spasial perkotaan cukup melekatkan makna pusaka dan memberikan fungsi terhadap tempattempat yang dilestarikan. Di pihak lain, Jivén \& Larkham (2003) mengkritik karena menganggap contoh-contoh penciptaan sense of place milik Ouf (2001) hanya terjebak pada konsep penciptaan tempat (place-making) untuk kepentingan promosi lingkungan fisik semata. Pelestarian kawasan pusaka perkotaan terkesan melupakan dimensi manusia, yaitu orang-orang yang berinteraksi dengan kawasan, termasuk warga lokal. Beberapa peneliti berargumen bahwa pendekatan pelestarian kawasan pusaka perkotaan saat ini memang masih mengabaikan dimensi manusia. Pendekatan pelestarian cenderung berfokus pada atribut fisik dan potensi komersial produk pelestarian daripada faktor manusia sebagai pengguna (Orbasli, 2000; Nasser, 2003). Menurut Orbasli (2000), dimensi manusia, yang penting untuk diperhatikan agar upaya pelestarian dapat berhasil, justru jarang terintegrasikan di dalam literatur-literatur pelestarian pusaka.

Perdebatan di atas menjelaskan kondisi penerjemahan konsep sense of place dalam pelestarian kawasan pusaka perkotaan itu masih terkesan ambigu. Apakah benar penerjemahan konsep ini hanya bermanfaat untuk perencanaan penciptaan-tempat semata dan mengabaikan dimensi manusia di dalam pelestarian? Apakah ada potensi lain dari sense of place yang juga bermanfaat bagi kepentingan pelestarian? Untuk menjawab pertanyaan tersebut, tulisan ini akan membahas 3 (tiga) buah topik terkait yaitu teori-teori mengenai pengertian sense of place, sense of place sebagai fokus pelestarian kawasan pusaka perkotaan, serta potensi sense of place lainnya dalam pelestarian kawasan pusaka perkotaan. Diskusi lalu dilanjutkan dengan penjelasan temuan-temuan penelitian di bagian Hasil. 
Ditemukan bahwa penerjemahan konsep sense of place dalam pelestarian kawasan pusaka di perkotaan tidak lah sekadar tentang dimensi fisik atau sebatas upaya penciptaan-tempat semata, tetapi juga berpotensi untuk dikaitkan dengan dimensi manusia. Selain bermanfaat sebagai panduan dalam perencanaan ruang kawasan pusaka yang memiliki perspektif lokal, konsep sense of place dalam pelestarian juga berpotensi sebagai faktor pendorong partisipasi warga dalam perencanaan pelestarian, dan sebagai prediktor perilaku masyarakat untuk melestarikan pusaka. Diharapkan, tulisan ini dapat memperkaya pemahaman konsep sense of place dalam teori-teori pelestarian pusaka serta membantu memberikan gambaran bagi para perancang dan perencana saat menyusun perencanaan pelestarian kawasan pusaka perkotaan yang berorientasi pada sense of place.

\section{METODE}

Pendekatan yang digunakan untuk mengeksplorasi potensi sense of place dalam pelestarian kawasan pusaka perkotaan ini adalah studi kepustakaan yang memuat hasil sintesis data-data sekunder penelitian yang telah diorganisasikan dan disusun secara sistematis. Studi kepustakaan adalah serangkaian kegiatan yang berkenaan dengan metode pengumpulan data pustaka, membaca, dan mencatat serta mengolah bahan penelitian (Zed, 2008). Data sekunder dalam penelitian ini merupakan hasil kajian dari penelitipeneliti sebelumnya mengenai topik sense of place di dalam konteks pusaka dan non-pusaka. Kajian ini dilakukan dengan menelaah dan membandingkan sumber-sumber kepustakaan untuk memperoleh data bersifat teoritis. Tulisan bersifat analisis deskriptif karena berupaya menguraikan data-data tentang sense of place, terutama dalam konteks pusaka, untuk kemudian dijelaskan dengan sistematis agar dapat dipahami dengan baik.

\section{PEMBAHASAN}

Bagian ini memberikan penjelasan mengenai pengertian sense of place, sense of place sebagai fokus pelestarian kawasan pusaka perkotaan, dan hasil-hasil penelitian terkait berbagai potensi sense of place, termasuk dari kajian-kajian berkonteks non-pusaka, yang dapat dimanfaatkan untuk kepentingan pelestarian kawasan pusaka perkotaan.

\section{Pengertian Sense of place}

Di dalam konteks perancangan kota, Montgomery (1998) menyatakan bahwa untuk menciptakan sense of place, maka sebuah tempat haruslah baik (a good place) dengan memiliki 3 (tiga) elemen yaitu form, activity, dan image. Teori Montgomery (1998) tersebut dijelaskan dalam Gambar 1.

Saat membicarakan form (bentuk), Montgomery (1998) merujuk pada pernyataan Punter (1991) bahwa bentuk adalah kualitas fisik yang terkait dengan lansekap dan lingkungan binaan. Dalam penelitiannya mengenai sense of place di Alvaneu Village Swiss Alpine, Kianicka dkk. (2006) menambahkan bahwa lingkungan binaan pusaka (built heritage) dan infrastruktur penunjang kegiatan pariwisata (tourism infrastructure) juga merupakan bagian dari elemen bentuk. Untuk activity (aktivitas), Montgomery (1998) menjelaskannya sebagai vitalitas sebuah tempat dalam mendukung beragam aktivitas di dalamnya. Elemen terakhir yaitu image (citra) dijelaskan sebagai kesan yang ditangkap oleh individu terhadap tempat yaitu hasil persepsi, termasuk pengetahuan, individu terhadap tempat tersebut. Merujuk teori Lynch (1981), pengetahuan yang mampu menghasilkan citra diperoleh dari kemampuan pengguna ruang mengidentifikasi 5 (lima) aspek fisik lingkungan kota yaitu paths, edges, districts, nodes, dan landmarks. Kombinasi pengetahuan tersebut, bersama dengan nilai dan keyakinan yang dimiliki, akan menghasilkan citra tempat yang negatif atau positif bagi individu. 


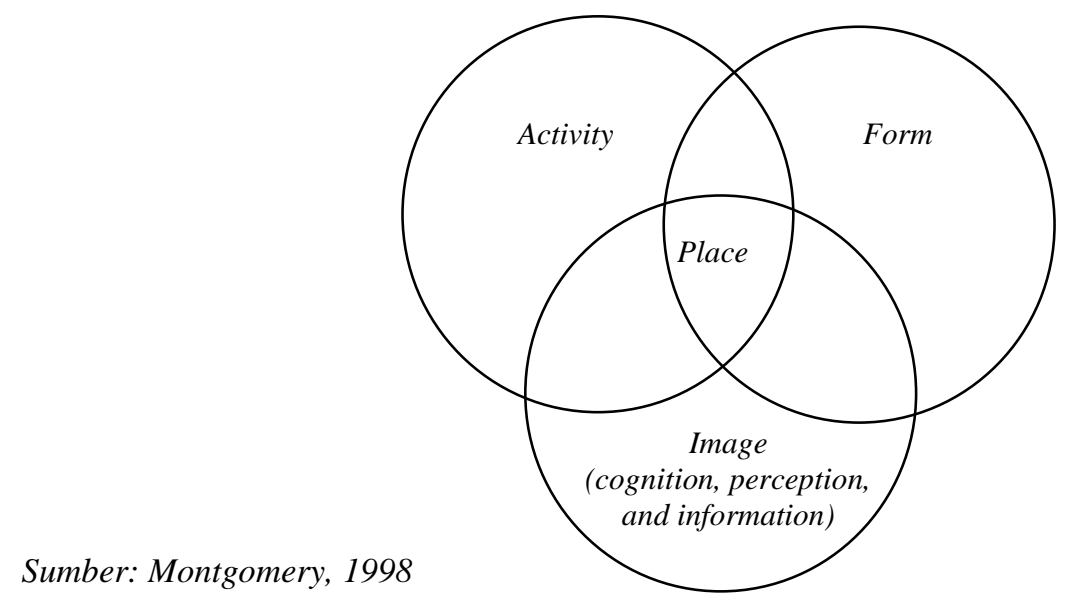

\section{Gambar 1. llustrasi 3 (Tiga) Elemen Tempat yang Dianggap Mampu Menghasilkan Sense of place di dalam Konteks Perancangan Kota}

Di satu sisi, teori Montgomery (1998) memang berhasil menjelaskan pendekatan dalam upaya menghadirkan sense melalui penciptaan-tempat yang didominasi kualitas aspek fisik lingkungan, tetapi di sisi lain, ketiga elemen tersebut belum menjelaskan definisi dari sense of place itu sendiri. Ketiga elemen tersebut hanyalah komponen tempat-tempat baik di perkotaan, sebagai syarat keberhasilan penciptaan-tempat, agar mampu menghasilkan sense of place. Definisi sense of place itu sendiri bukanlah pada elemen-elemen tersebut akan tetapi pada ikatan yang terjalin antara manusia dan tempat setelah manusia mampu mengidentifikasi bentuk ruang, melakukan aktivitas di ruang tersebut, dan memiliki kesan terhadap ruang tersebut. Sense of place tidak berada dalam elemen-elemen tersebut tetapi dalam interaksi manusia dengan elemen-elemen tersebut (Carmona dkk., 2003). Ketiga elemen tersebut sebenarnya lebih tepat digunakan untuk menjelaskan faktorfaktor yang berpotensi menghasilkan sense of place seseorang.

Dalam perkembangan kajian sense of place selanjutnya, teori Montgomery (1998) ternyata masih belum lengkap karena ditemukan berbagai elemen lain yang juga dianggap berpotensi menghasilkan sense of place. Graham dkk. (2009) memberikan catatan bahwa hubungan antar manusia di dalam sebuah tempat, mungkin saja bahkan lebih penting dibandingkan dengan interaksi manusia dengan lingkungan binaan. Stedman (2003) menyebutnya dengan ikatan sosial sementara Hashemnezhad dkk. (2013) memakai istilah faktor sosial. Smith (2011) menyatakan bahwa keterlibatan individu dalam masyarakat akan memberikan kesempatan bersosialisasi dan membentuk ikatan yang berpotensi meningkatkan sense of place. Oleh karena itu, Hashemnezhad dkk. (2013) meyakini bahwa elemen fisik dan sosial berperan sama pentingnya dalam menghasilkan sense of place.

Dalam beberapa kajian berkonteks non-pusaka, telah hadir pemahaman bahwa sense of place merupakan hasil interpretasi individu terhadap lingkungan (lihat Williams \& Stewart, 1998; Hummon, 1992; Stedman, 2003). Sense of place tidak langsung terbentuk hanya karena keberadaan sebuah lokasi tertentu namun berasal dari keterlibatan manusia dengan lokasi tersebut (Smith, 2011). Kajian Cottrell \& Cottrell (2015) dalam konteks pariwisata, dan (Stedman, 2002) dalam konteks psikologi lingkungan, menyatakan bahwa sense of place adalah konsep multidimensi yang merepresentasikan emosi, keyakinan, makna, keterikatan, kepuasan, dan komitmen terhadap sebuah tatanan ruang (spatial setting). Karena itu, Jorgensen \& Stedman (2001), para peneliti yang berlatar psikologi lingkungan, yakin bahwa konsep sense of place sebenarnya memiliki kemiripan dengan konsep sikap (attitude) sehingga mereka memberikan teori bahwa sense of place adalah kumpulan sikap yang terkonstruksi dari place identity, place attachment, dan place dependence. 
Place identity adalah kumpulan keyakinan hasil persepsi kognitif, antara lain pemikiran atau keyakinan tentang tempat; place attachment adalah ikatan emosional positif antara manusia dengan tempat sebagai hasil persepsi afektif; sedangkan place dependence adalah keterikatan pengunjung, hasil persepsi konatif, terhadap fungsional tempat yang mendukung kegiatan di dalamnya (Altman \& Low, 1992; Jorgensen \& Stedman, 2001; 2006). Beberapa peneliti menyatakan kemudian bahwa konstruksi tersebut dapat dianggap sebagai acuan terbaik untuk meneliti (lihat Nanzer, 2004; Vong, 2013).

\section{Sense of place Sebagai Fokus Pelestarian Kawasan Pusaka Perkotaan}

Lingkungan bersejarah berperan menghadirkan sense of place karena dianggap memiliki ciri khas (distinctiveness) sehingga mampu memberikan harga diri (self-esteem), kontinuitas terhadap masa lalu (sense of continuity), serta identitas (sense of identity) bagi masyarakat di lingkungan tersebut (Bradley dkk., 2009; English Heritage, 2009; Graham dkk., 2009; Hawke, 2011). Pusaka dan sense of place berhubungan erat, bahkan disebut bahwa pusaka mampu mendefinisikan sense of place (Department of the Environment and Heritage Australia, 2001 dalam Vong, 2013). Oleh karena itu, hubungan pusaka perkotaan dengan sense of place bukanlah topik yang baru secara gagasan (lihat tulisan Ford, 1974); walaupun kajian mengenai hubungan keduanya baru hadir secara eksplisit sekitar 15 (lima belas) tahun terakhir (English Heritage, 2009; Hawke, 2010). Kondisi ini terjadi karena pada awalnya, konsep sense of place dalam perencanaan pusaka belum dianggap penting akibat kebijakan dan intervensi perencanaan pelestarian yang masih cenderung berfokus pada fisik bangunan dan ruang berskala kecil (Nasser, 2002). Namun, sejalan dengan perkembangan pelestarian, konsep sense of place mulai menjadi pusat perhatian dalam diskusi perencanaan saat ini (Hague \& Jenkins, 2004); dan menjadi salah satu fokus perencanaan kawasan pusaka. Kondisi ini secara eksplisit mengungkapkan adanya kebutuhan untuk memperluas substansi dan cakupan desain ruang publik yang lebih dari sekadar "penampilan eksternal" serta adanya pergeseran fokus pada persepsi publik dan penciptaan pengalaman (Martokusumo, 2015).

Gagasan sense of place sebagai fokus pelestarian kawasan pusaka di perkotaan pun kemudian ditulis eksplisit oleh Ouf (2001) dalam konteks perancangan kota. Ouf (2001) yakin bahwa identitas sejarah perkotaan berasal dari karakter fisik perkotaan sehingga sense of place, yang dianggap mampu memperkuat identitas tersebut, harus dihadirkan melalui selektivitas pemilihan lokasi, elemen perkotaan, serta fitur-fitur sitescape yang harus dipertahankan. Menurut Ouf (2001), konsepnya adalah memberikan makna pusaka dan fungsi terhadap place yang dilestarikan agar dapat dipahami dan diimajinasikan oleh masyarakat, seperti pernyataannya: "The concept is simple, as it means that urban conservators/designers need to focus on attaching a heritage meaning and function to the conserved place so that it becomes understandable and imageable to the general public".

Penciptaan sense of place di kawasan pusaka perkotaan diyakini akan menghasilkan esensi kuat dari keberadaan pusaka sehingga mampu menimbulkan upaya pelestarian yang berkelanjutan. Namun, penggunaan istilah "understandable" dan "imageable" yang sebenarnya sangat subjektif tersebut, terkesan mereduksi diversitivitas kemampuan masyarakat dalam memaknai kawasan. Sense of place, walaupun terkait dengan pengaturan ruang, sebenarnya lebih merupakan hasil pemaknaan individu atau masyarakat terhadap simbol-simbol ruang tersebut berdasarkan nilai sosial budaya yang mereka miliki (Jorgensen \& Stedman, 2001). Dengan demikian, sense of place bukan semata ditentukan karena faktor lingkungan, tetapi juga dipengaruhi oleh nilai-nilai yang dianut individu. Pemahaman ini lah yang masih belum hadir dalam upaya perencanaan saat meletakkan sense of place sebagai fokus pelestarian. Masih terdapat titik buta (blind spot) dalam perkembangan teori sense of place, salah satunya adalah kurangnya pemahaman bahwa makna sebuah tempat adalah produk gabungan dari fitur lingkungan dan atribut individu 
(Raymond dkk. 2017). Menurut Masterson dkk. (2017), konsep sense of place seharusnya menjadi sumber wawasan yang kaya mengenai hubungan manusia dengan realita-realita yang terjadi di lingkungannya. Tak heran bila di dalam perkembangan pendekatan perencanaan pusaka, Jivén \& Larkham (2003) memberi kritik bahwa pemakaian konsep sense of place pada akhirnya hanya mementingkan bentuk fisik tempat untuk kepentingan pasar wisatawan semata tanpa mempertimbangkan kepentingan warga lokal. Perdebatan ini menunjukkan bahwa gagasan mengenai penciptaan-tempat yang berorientasi pada kehadiran sense of place merupakan hal-hal yang harus ditinjau kembali dalam perencanaan kawasan pusaka di perkotaan.

\section{Potensi Sense of place di dalam Pelestarian Kawasan Pusaka Perkotaan}

Sejalan dengan perkembangan pendekatan pelestarian pusaka, ketertarikan untuk mengkaji kontribusi sense of place di dalam wacana pusaka pun mulai hadir (Hawke, 2010). Namun tidak banyak literatur akademik yang secara eksplisit menjelaskan potensi sense of place bagi manusia dalam mendukung pelestarian kawasan pusaka. Literatur tentang pelestarian pusaka justru mencerminkan kesenjangan karena masih lebih berfokus pada atribut fisik dan potensi komersial produk pelestarian daripada faktor manusia (Nasser, 2002). Di pihak lain, literatur akademik berkonteks non-pusaka justru telah mulai menyadari, meskipun secara implisit, beberapa potensi sense of place yang dapat dimanfaatkan dalam perencanaan spasial. Berdasarkan berbagai kajian, dengan beragam konteks yang ada dalam literatur akademik, ditemukan 3 (tiga) buah potensi yang dapat dimanfaatkan untuk mendukung hadirnya dimensi manusia dalam pelestarian kawasan pusaka di perkotaan:

1. Sense of place Sebagai Informasi Panduan dalam Perencanaan Spasial Kawasan Pusaka Perkotaan

Para perancang kota dan administrator kota kini mulai tertarik pada keberadaan sense of place dan kekuatan place, serta berbagai fenomena perkotaan lainnya, yang mencerminkan adanya kepercayaan bahwa tempat mendukung identitas (Martokusumo, 2011). Dilihat dari substansi, pelestarian berbasis kawasan memang jauh lebih kompleks dibandingkan pada tahap awal yang terbatas pada bangunan tunggal (Martokusumo \& Zulkaidi, 2014). Dalam konteks wilayah, Puren dkk. (2007) berargumen bahwa sense of place merupakan sebuah masukan penting dalam perumusan proposal perencanaan tata ruang bagi kawasan pusaka Vrederoft Dome di Afrika Selatan. Menurut Puren dkk. (2007), karena intervensi perencanaan dan desain harus peka terhadap konteks spasial, maka pengetahuan mengenai sense of place dapat dijadikan informasi panduan dalam perencanaan ruang kawasan.

Sense of place merupakan bentuk perwujudan cara pandang seseorang terhadap pusaka berwujud (tangible) dan tak berwujud (intangible) dalam kawasan. Cara pandang para individu mengenai lingkungannya tersebut merupakan prasyarat untuk desain dan implementasi kebijakan yang efektif sehingga dapat berimplikasi terhadap pedoman penataan ruang (Puren dkk., 2007). Ketika mengaplikasikan sense of place sebagai panduan, maka perencanaan akan mampu mengidentifikasi batas-batas kawasan pusaka yang menjadi tempat orientasi karena berkarakter pusaka paling kuat. Selain itu, pengetahuan mengenai sense of place terhadap kawasan juga akan mampu memberi gambaran tentang seberapa kuat daya tarik yang dimiliki kawasan tersebut. Memahami aspek fundamental dari sense of place dapat membantu penilaian tingkat ketertarikan publik terhadap suatu tempat (Hashemnezhad dkk., 2013). Hal ini akan berimplikasi, antara lain pada upaya delineasi kawasan, perletakan pemintakatan kawasan, pola arus lalu-lintas, hingga aksesibilitas pengunjung di dalam kawasan pusaka. Menjadikan sense of place sebagai panduan dalam mendesain kawasan pusaka juga akan memberikan alternatif desain fisik kawasan saat para perencana dan perancang memiliki pengetahuan mengenai bentuk- 
bentuk berwujud yang dianggap pusaka oleh masyarakat. Dalam konteks pelestarian, pengetahuan tersebut menjadi masukan penting untuk membantu perencanaan kawasan pusaka yang telah mengalami degradasi lingkungan agar dapat dilestarikan tanpa menghilangkan identitas kawasan.

\section{Sense of place Mendorong Partisipasi Warga Lokal dalam Perencanaan Spasial Kawasan Pusaka Perkotaan}

Berbagai penelitian di negara-negara maju membuktikan secara empiris bahwa persepsi masyarakat terhadap lingkungan mempengaruhi tingkat partisipasi masyarakat terhadap perencanaan tata ruang (Poerwoningsih dkk.,2016). Karena sense of place merupakan kumpulan dari berbagai persepsi manusia mengenai lingkungannya, maka sense of place semestinya dapat berimplikasi terhadap tingkat partisipasi masyarakat dalam perencanaan lingkungan yang menjadi tempat manusia beraktivitas. Semakin kuat sense of place yang dimiliki individu, maka semakin besar dependence, commitment and desire suatu komunitas untuk terlibat dalam pengelolaan kawasan (Axford \& Hockings, 2005). Di dalam konteks kawasan lindung, Axford \& Hockings (2005) menjelaskan bahwa sense of place dapat dijadikan sebagai alat untuk menilai keterlibatan komunitas walaupun diakui bahwa komunitas lokal terkait kawasan lindung umumnya adalah masyarakat rural yang homogen, dan bukan heterogen seperti dalam konteks perkotaan.

Dalam konteks perencanaan, sense of place dan perilaku lingkungan individu dianggap memiliki pengaruh positif dalam keberhasilan tahapan proses perencanaan kolaboratif (Kolodziejski, 2014; Thompson \& Prokopy, 2016). Menurut Jorgensen \& Stedman (2006), pengetahuan mendalam mengenai hubungan sense of place dengan aksi komunitas dapat dimanfaatkan dalam arena perencanaan sebuah tempat karena dapat membantu upaya pengembangan kebijakan (policy development), implementasi, dan penerimaan kebijakan oleh masyarakat (implementation and acceptability by the public). Di dalam konteks pusaka, English Heritage (2009) juga sependapat bahwa sense of place dapat mendorong keterlibatan individu dan kelompok di dalam kawasan pusaka untuk terlibat dalam pembentukan kebijakan lokal, melalui pernyataannya:

"Increasing local belonging or strengthening people's sense of where they live (their sense of place) can have many positive benefits, including increasing their sense of self-esteem and identity, which in turn can lead to stronger communities, in which individuals and groups are actively involved in local decision making."

Keterlibatan masyarakat tersebut terjadi karena adanya kepentingan untuk melestarikan sense of place, demi mendukung keberlanjutan identitas lokal yang dimiliki masyarakat. Beatley \& Manning (1997) menyatakan bahwa konektivitas masyarakat terhadap masa lalu serta bagaimana konektivitas tersebut memengaruhi sense of place merupakan sebuah dimensi penting dalam penguatan identitas lokal dan dalam mempertahankan keberadaan masyarakat. Menurut Williams (2014), konteks dan kondisi lokal memang merupakan hal penting untuk membentuk makna terhadap sebuah tempat. Makna yang dimiliki kawasan sering dikaitkan dengan tempat-tempat yang akrab dan penting secara historis, juga mampu memberikan rasa stabilitas dan keamanan bagi penduduk perkotaan (Shinbira, 2012). Kualitas-kualitas ini sangat penting untuk dijaga demi kelangsungan hidup budaya suatu masyarakat. Dengan demikian, dapat dipahami bila warga yang memiliki sense of place akan terdorong untuk berpartisipasi dalam perencanaan pelestarian kawasan pusaka demi upaya menjaga identitas.

3. Sense of place Memiliki Hubungan dengan Perilaku Melestarikan Kawasan Pusaka Perkotaan

Berbagai literatur yang berupaya menghubungkan sense of place dengan berbagai indikator perilaku sebenarnya telah mulai hadir sejak tahun 1960 -an terkait isu pelestarian lingkungan alam dan dampak pembangunan (Hague \& Jenkins, 2004; Graham dkk., 2009). 
Literatur akademik yang mengkaji hubungan tersebut, umumnya masih seputar konteks pelestarian lingkungan alam seperti kawasan hutan dan cagar alam (lihat Gosling \& Williams, 2010; Ramkissoon dkk., 2012; Ardoin, 2014). Meskipun literatur yang menunjukkan hubungan sense of place dan perilaku manusia untuk melestarikan, lebih banyak dalam konteks perencanaan lingkungan alam, tetapi menarik untuk mempertimbangkan hubungan ini dalam konteks perencanaan pusaka. Penelitian yang berkonteks kawasan pusaka akan berpotensi menghasilkan hal baru dan unik karena perbedaan lokasi yaitu kawasan yang bersignifikansi budaya serta adanya konteks perkotaan dengan nilai sosial budaya yang lebih dinamis. Sayangnya, diskursus dalam konteks pusaka ini masih terbatas akibat masih banyaknya perdebatan seputar hubungan sense of place dan perilaku melestarikan itu sendiri. Masih terdapat perdebatan dalam penyelidikan sehingga sulit menarik kesimpulan pasti tentang mengapa, bagaimana, dan dalam konteks apa, sense of place mampu berkontribusi pada perilaku pro-lingkungan (Scannell \& Gifford, 2010; Ramkissoon dkk., 2012).

Di satu sisi, beberapa kajian meyakini bahwa sense of place berpotensi menjadi prediktor perilaku melestarikan pusaka. Salah satunya adalah Buonincontri, dkk. (2017) yang menyatakan bahwa sense of place mampu memengaruhi pengunjung kawasan pusaka untuk memiliki perilaku berkelanjutan (sustainable behaviour of visitors). Meskipun begitu, Raymond dkk. (2017) mengkritik kajian-kajian dalam literatur akademik tersebut karena menganggap hubungan sense of place dan perilaku yang dihasilkan bukanlah sebuah bentuk yang dinamis, sebagai hasil kombinasi antara pikiran (mind), budaya (culture), dan lingkungan (environment). Menurut Jorgensen \& Stedman (2001), literatur yang tersedia mengenai hubungan sense of place dan perilaku melestarikan memang masih sedikit, terfragmantasi, dan berantakan. Walaupun masih terdapat area yang terabaikan dalam teori sense of place terkait implikasinya terhadap perilaku (Stedman, 2002); namun tidak tertutup kemungkinan bahwa sense of place berpotensi menjadi prediktor perilaku dalam konteks pusaka sehingga dibutuhkan kajian lebih lanjut untuk membuktikan hubungan kedua variabel tersebut.

\section{HASIL DAN PEMBAHASAN}

Berdasarkan diskusi dalam bagian pembahasa di atas, ditemukan beberapa hal penting yang dapat digali lebih dalam untuk menjawab pertanyaan penelitian dalam tulisan ini:

Pertama, konsep sense of place cenderung akan selalu mengundang perdebatan karena sifatnya yang absurd dan subjektif. Berbagai kajian yang ada cenderung menilai berdasarkan pemahaman bahwa sense of place adalah mengenai kualitas ruang fisik semata dan melupakan bahwa konsep ini sebenarnya berbicara tentang sense dalam diri manusia sebagai hasil interaksi antara manusia dan sebuah tempat yang bermakna. Dengan demikian, definisi sense of place akan lebih tepat bila merujuk pada kumpulan sikap yang dimiliki manusia sebagai hasil penilaiannya dengan tempat tersebut. Karena itu, konsep ini akan terlihat lebih jelas dan sistematis saat dikaji menggunakan pendekatan sikap dari Jorgensen \& Stedman (2001) dalam ranah kajian psikologi lingkungan. Sense of place tidak berbicara tentang kualitas lingkungan fisik semata melainkan adalah sebuah kumpulan sikap, kombinasi dari hasil penilaian manusia terhadap lingkungan fisik dan sosial tempat (place identity), yang menghasilkan sebuah ikatan emosional (place attachment), sehingga mendorong manusia untuk memiliki sebuah ketergantungan positif (place dependency) terhadap tempat tersebut. Place identity, place attachment, dan place dependence ini merupakan hasil persepsi kognitif, afektif, dan konatif manusia terhadap lingkungan fisik atau lingkungan sosial tempat manusia tersebut beraktivitas. Karena itu, saat berbicara mengenai tempat, mau tidak mau, harus berbicara mengenai lingkungan fisik dan sosial yang dimiliknya., sehingga elemen-elemen yang menghasilkan sense of place, semestinya berasal dari kedua lingkungan tersebut. 
Walaupun awalnya konsep sense of place hadir sebagai hasil gagasan-gagasan peneliti geografi, tetapi harus diakui bahwa konsep ini telah banyak berkembang dalam disiplin ilmu psikologi. Namun demikian, tetap dibutuhkan sebuah pemahaman yang multidisiplin untuk memahami konsep ini. Puren dkk. (2007) berpendapat bahwa konsep sense of place tidak dapat diinterpretasikan sendiri hanya mengggunakan kajian ilmu psikologi karena sense of place akan selalu berhubungan dengan lingkungan spasial. Karena itu, dibutuhkan kajian-kajian yang lintas disiplin untuk mendapatkan pemahaman konsep yang lebih kaya dan komprehensif untuk mampu menjawab berbagai isu permasalahan yang terjadi antara manusia dengan lingkungannya, baik berupa lingkungan alam atau lingkungan binaan dalam berbagai konteks.

Kedua, perdebatan mengenai tuduhan-tuduhan bahwa penerjemahan konsep sense of place dalam pelestarian kawasan pusaka di perkotaan telah mengabaikan dimensi manusia, sebenarnya berpotensi terjadi akibat perbedaan pemikiran Ouf (2001) dengan Jivén \& Larkham (2003) mengenai identitas pemilik sense of place di kawasan pusaka perkotaan. Harus disadari bahwa pengguna tempat dalam pemikiran Ouf (2001) adalah para pengunjung sementara Jivén \& Larkham (2003) merujuk pada warga lokal yang sehari-hari beraktivitas di dalam tempat. Meskipun isu mengenai siapa pemilik sense of place di kawasan pusaka itu memiliki perdebatannya sendiri tetapi perkembangan penelitian di kemudian hari menunjukkan bahwa sense of place mungkin saja dimiliki oleh warga lokal dan pengunjung (lihat Kianicka dkk., 2006).

Bagi pengunjung, tempat yang mereka kunjungi mengekspresikan pesan, nilai, ide, dan lansekap yang berbeda dengan pengalaman yang telah diketahui dari tempat mereka sendiri (Davis dkk., 2010). Karena itu, pengunjung sebenarnya berpotensi untuk memberikan makna pada kawasan yang mendapatkan penciptaan-tempat. Sayangnya, bagi warga lokal, upaya penciptaan-tempat ini diduga tidak berpengaruh signifikan karena sedari awal, warga lokal telah memiliki sense of place terhadap kawasan tempat mereka tinggal dan beraktivitas sehari-hari. Sense of place timbul karena rasa memiliki (sense of belonging) (Hawke, 2011) atau social insideness karena adanya keakraban dengan lansekap dan masyarakat di tempat tersebut (Relph, 1976). Warga lokal yang telah menetap lama dianggap mampu memiliki sense of place karena lamanya durasi menetap di sebuah tempat. Kianicka dkk. (2006) menjelaskan dalam penelitiannya di Swiss Alpine Village, bahwa sense of place penduduk lokal, selain terkait dengan kehidupan sehari-hari seperti pekerjaan, properti, ikatan sosial, juga terkait dengan kenangan masa kecil dan remaja, sedangkan sense of place wisatawan terbentuk karena estetika dan karakteristik tempat yang diterima saat mendapatkan pengalaman dari kegiatan rekreasi.

Penjelasan di atas memberi pemahaman bahwa, meskipun dikritik, upaya menghadirkan sense of place melalui penciptaan-tempat tetap dibutuhkan dalam perencanaan pelestarian kawasan pusaka karena mampu memengaruhi sense pengunjung. Penciptaan-penciptaan pengalaman di ruang-ruang fisik yang berkarakter sejarah, seperti yang ditekankan oleh Ouf (2001) dan Martokusumo (2015), tetap diperlukan agar para pengunjung dapat memaknai tempat dan memiliki sense of place yang positif terhadap kawasan pusaka di perkotaan. Namun, saat intervensi fisik dianggap hanya efektif bagi pengunjung, menjadi penting untuk kemudian memikirkan seperti apakah bentuk intervensi perencanaan yang efektif membangun kembali sense of place warga lokal. Menurut Jivén \& Larkham (2003), sense of place tidak dapat diciptakan oleh intervensi profesional sehingga pelestarian seharusnya berfokus pada penciptaan aktivitas untuk memunculkan sense of place, yang memang telah ada sebelumnya. Dalam lingkup ini, gagasan yang berfokus pada aktivitas terkait pusaka semestinya dapat menjadi salah satu alternatif substansi perencanaan yang patut dipertimbangkan untuk membangkitkan kembali sense of place milik warga lokal. Aktivitas-aktivitas seperti kegiatan penelusuran kehidupan masa lalu yang terkait dengan artefak dan penggalian kisah-kisah (lihat MorelEdniebrown, 2011) atau aktivitas pusaka seperti pengumpulan kisah sejarah oleh warga, 
meneliti ulang sejarah lokal untuk ditulis kembali, membuat pameran sejarah lokal serta selebaran interpretasi tentang pusaka (lihat Hawke, 2010) dianggap berpotensi membangkitkan kembali sense of place warga lokal. Hawke (2010) yakin, individu-individu yang terlibat dengan kawasan pusaka dapat mengeksplorasi sense of place mereka melalui berbagai aktivitas tersebut. Morel-Edniebrown (2011) juga menjelaskan hal tersebut terkait revitalisasi kawasan bersejarah Northbridge di Perth Australia, yang melibatkan warga lokal untuk bersama-sama mengungkap sejarah Northbridge. Kegiatan tersebut pada akhirnya mengubah persepsi dan mengembangkan kesadaran bahwa kawasan mereka ternyata memiliki karakter budaya yang berbeda dan unik. Menemukan dan menyediakan sejarah wilayah yang beragam ini telah menciptakan rasa identitas baru (MorelEdniebrown, 2011). Sejalan dengan teori tersebut, Davis dkk.(2010) juga menyatakan bahwa pada awalnya, berbagai aktivitas dan gerakan para perempuan warga lokal di Tisban Taiwan lah yang memulai terbangunnya kembali identitas diri milik warga terhadap tempat mereka tinggal.

Ketiga, hasil pembahasan telah membuktikan bahwa sense of place memiliki beragam potensi yang dapat dimanfaatkan demi mendapatkan pelestarian kawasan pusaka di perkotaan yang berkelanjutan, dan bukan sekadar hanya untuk penciptaan-tempat semata. Sense of place berpotensi menjadi sumber pengetahuan penting bagi para perencana untuk menyusun pelestarian pusaka yang berdimensi manusia, yaitu pelestarian yang mampu mengakomodir perspektif manusia yang berinteraksi dengan kawasan. Perspektif manusia tersebut sangat perlu untuk dipertimbangkan karena adanya kebutuhan untuk menjaga keberlanjutan nilai-nilai signifikansi budaya yang dimiliki oleh kawasan pusaka di perkotaan. Pelestarian tidaklah sekadar mempertahankan fisik namun juga menjaga nilainilai signifikansi budaya kawasan karena nilai-nilai itulah yang akan membantu intervensi dalam pelestarian (Feilden, 2003). Dalam proses perencanaan pelestarian kawasan pusaka, hal pertama yang perlu dilakukan adalah memahami nilai-nilai signifikansi budaya dari sebuah tempat, untuk kemudian membuat kebijakan, dan akhirnya mengelola place tersebut sesuai dengan kebijakan yang ditetapkan berdasarkan pada pemahaman terhadap signifikansi budayanya (Australia ICOMOS, 2013). Agar nilai-nilai tersebut dapat diterjemahkan dengan baik ke dalam upaya-upaya pelestarian pusaka, maka perencanaan dituntut untuk mampu mengidentifikasi nilai-nilai signifikansi budaya kawasan pusaka melalui perspektif masyarakat.

Persepektif manusia terhadap nilai-nilai tersebut terwujud dalam bentuk sense of place yang mereka miliki sebagai hasil pemaknaan terhadap karakter, keunikan, dan identitas kawasan pusaka. Karena itu, memiliki pengetahuan tentang sense of place yang ada dalam kawasan akan membantu perencana memahami signifikansi budaya kawasan sehingga berpotensi menghasilkan perencanaan pelestarian yang berkelanjutan. Kondisi ini yang membuat Orbasli (2000) yakin bahwa signifikansi tempat, kualitas uniknya (semua faktor yang menjadikan tempat tersebut istimewa), serta pengetahuan mengenai sense of place yang dimiliki manusia terhadap tempat tersebut, haruslah dipahami dalam perencanaan pelestarian kawasan pusaka. Selain akan mendapatkan gambaran tentang keistimewaan sebuah tempat serta mengetahui bagaimana cara memperbaiki tempat tersebut (Relph, 1976), perencanaan yang bersedia mempertimbangkan sense of place kawasan akan mewujudkan sebuah peluang bagi perkembangan nilai lokalitas yang unik untuk masuk dan berperan dalam pelestarian pusaka. Nagel (1986) menggambarkan perspektif ini sebagai "the perspective of a particular person inside the world" yang sangat dibutuhkan untuk memperluas fokus perencanaan yang cenderung menggunakan perspektif yang disebutnya sebagai "view from nowhere". Dengan demikian, pengetahuan mengenai seperti apakah sense of place warga yang menjadi pelaku pelestarian dapat memandu para perencana mendapatkan strategi perencanaan yang sesuai konteks lokal.

Selain berpotensi sebagai input pelestarian kawasan pusaka di perkotaan, termasuk dalam perencanaan spasial kawasan, penciptaan-tempat dan penciptaan aktivitas 
pelestarian, konsep sense of place ini juga berpotensi besar menjadi faktor pendorong keterlibatan manusia untuk berperan dalam kegiatan-kegiatan pelestarian. Di satu sisi, konsep sense of place jelas berbicara tentang manusia; sementara di sisi lain, manusia sebagai pelaku pelestarian merupakan salah satu faktor penentu keberhasilan atau kegagalan pelestarian pusaka (Nasser, 2002). Kegagalan pelestarian ini, bila dilihat dari sisi pelaku, antara lain karena kondisi sosial ekonomi, rendahnya kesadaran, dan kepedulian, minimnya pengetahuan, serta keterbatasan pengelola secara administratif (Martokusumo, 2002). Sense of place diduga terkait dengan kepedulian sehingga berpotensi menjadi prediktor perilaku melestarikan. Masyarakat mungkin memahami nilai kognitif suatu perencanaan akan tetapi jika mereka tidak memiliki ikatan emosional yang memicu keinginan mereka untuk mengikuti perencanaan tersebut maka perencanaan itu sulit berhasil (Nussbaum, 2003; Hoch, 2006). Manzo \& Perkins (2006) juga menjelaskan bahwa aspek emosional dari tempat seringkali diabaikan dalam proses partisipatif sehingga kehilangan aspek penting yang dapat membuat perencanaan menjadi lebih "membumi". Karena itu, dibutuhkan pelaku-pelaku pelestarian yang memiliki sense of place positif agar terdorong untuk terlibat dalam kegiatan-kegiatan pelestarian.

\section{KESIMPULAN}

Konsep sense of place telah mulai diperhitungkan di dalam upaya pelestarian kawasan pusaka perkotaan akan tetapi penerjemahan konsep ini dalam fokus pelestarian kawasan pusaka masih mendapat kritik karena dianggap telah terjebak pada dimensi fisik semata dan mengabaikan dimensi manusia. Perdebatan hadir karena penerjemahan konsep sense of place yang masih dianggap ambigu dalam pelestarian kawasan pusaka Di sisi lain, dalam konteks pusaka, masih sulit ditemukan literatur akademik yang membahas eksplisit mengenai berbagai potensi lain yang dapat diberikan konsep ini untuk mendukung pelestarian kawasan. Karenanya, dibutuhkan sebuah kajian untuk meninjau ulang kedudukan konsep ini dalam konteks pelestarian pusaka, seperti yang diakui oleh Jivén \& Larkham (2003) melalui pernyataannya: "Conservationists and urban designers in particular need to revisit the theoretical underpinnings of the terms and concepts that they employ, in order fully to understand the potential contributions of sense of place, authenticity and character".

Berdasarkan hasil temuan, kehadiran sense of place dalam pelestarian kawasan pusaka di perkotaan ternyata tidak hanya bermanfaat untuk dimensi fisik pelestarian semata, tetapi juga berperan menghadirkan dimensi manusia. Fokus pada dimensi manusia ini menjadi penting karena publik yang mengkonsumsi ruang-ruang di kawasan pusaka perkotaan tersebut bukanlah tunggal akan tetapi memiliki identitas yang berbeda. Perhatian ini dapat diterjemahkan sebagai upaya penciptaan-tempat demi kepentingan pengunjung, tanpa melupakan juga upaya perencanaan aktivitas yang mampu melestarikan nilai-nilai tak wujud (intangible) di kawasan pusaka demi membangun kembali sense of place warga lokal. Dengan kata lain, pelestarian dengan sense of place semestinya mampu memberikan bobot seimbang, antara perbaikan fisik tempat dan keterlibatan manusia pengguna kawasan pusaka di perkotaan. Untuk mendukung hal tersebut, dibutuhkan pengetahuan para perencana mengenai konteks dan kondisi lokal, serta pengalaman-pengalaman spesifik dari tempat-tempat dalam kawasan pusaka, yang dianggap unik dan bermakna, untuk warga lokal serta bagi pengunjung yang datang.

Konsep sense of place terbukti berpotensi menjadi bahan panduan perencanaan spasial kawasan pusaka di perkotaan, untuk mengakomodir perspektif pengguna kawasan, yaitu mereka yang tinggal, berkunjung, dan beraktivitas di dalam kawasan. Konsep ini juga mampu memberikan informasi mengenai seberapa besar kesediaan warga lokal yang bersedia terlibat dalam tahap-tahap perencanaan pelestarian, serta memberikan gambaran perilaku melestarikan pusaka dari warga dan pengunjung karena sense of place diyakini dapat menjadi prediktor bagi perilaku-perilaku tersebut. Sense of place yang menonjol dapat menjadi sumber daya yang berharga bagi perencana, pembuat keputusan, profesional, dan 
bagi komunitas itu sendiri, karena pihak-pihak tersebut akan dapat menemukan cara membangun tempat yang berkelanjutan (Kolodziejski, 2014).

Pengetahuan mengenai potensi-potensi sense of place tersebut akan menjadi informasi penting bagi para perencana, pengambil keputusan, praktisi, dan komunitas, untuk menemukan cara membangun kawasan bernilai pusaka sebagai sebuah tempat yang berkelanjutan di masa-masa mendatang. Hal ini sesuai dengan penjelasan Duxbury dkk., (2007) yang menyatakan bahwa kepemilikan sense of place merupakan salah satu karakter komunitas yang berkelanjutan karena mampu memberdayakan warga untuk mengambil keputusan atas lingkungan, sumber daya, dan masa depan mereka sendiri. Untuk itu, dibutuhkan penerjemahan konsep sense of place yang tepat dalam pelestarian kawasan, yaitu yang sesuai dengan konteks serta nilai lokal, untuk mampu mengidentifikasi dan menghasilkan pelaku-pelaku pelestarian yang dapat merencanakan, memelihara, mengembangkan dan memanfaatkan objek pelestarian tersebut sehingga keberadaan kawasan pusaka di perkotaan akan selalu berkelanjutan.

\section{DAFTAR PUSTAKA}

Altman, I., \& Low, S. (1992). Human behavior and environments: Advances in theory and research. Place Attachment, 12.

Ardoin, N. M. (2014). Exploring Sense of Place and Environmental Behavior at an Ecoregional Scale in Three Sites. Human Ecology, 42(3), 425-441. https://doi.org/10.1007/s10745-014-9652-x

Australia ICOMOS. (2013). The Burra Charter: the Australia ICOMOS Charter for Places of Cultural Significance. Retrieved from http://portal.iphan.gov.br/uploads/ckfinder/arquivos/The-Burra-Charter-2013Adopted-31_10_2013.pdf

Axford, J. C., \& Hockings, M. T. (2005). Sense of Place-A Tool to Assist the Meaningful Engagement of Communities in Protected Area Management. In D. Gardiner \& K. Scott (Eds.) (Ed.), Proceedings of International Conference on Engaging Communities (pp. 1-17). RoadsBrisbane: AU: Queensland Department of Main.

Beatley, T., \& Manning, K. (1997). The Ecology of Place: Planning for Environment, Economy and the Community.

Bott, S. E., \& Banning, J. H. (2008). The Use of Psychometric Scales to Measure Spirit of Place Relevance to Heritage Conservation Efforts from Ninewa Province, Iraq. 16th General Assembly and Scientific Symposium of ICOMOS. Retrieved from https://www.icomos.org/quebec2008/cd/toindex/77_pdf/77RrEt-92.pdf

Bradley, D., Bradley, J., Coombes, M., \& Tranos, E. (2009). Sense of Place and Social Capital and the Historic Built Environment.

Buonincontri, P., Marasco, A., \& Ramkissoon, H. (2017). Visitors' experience, place attachment and sustainable behaviour at cultural heritage sites: A conceptual framework. Sustainability (Switzerland), 9(7). https://doi.org/10.3390/su9071112

Carmona, M., Heath, T., Oc, T., \& Tiesdell, S. (2003). The Dimensions of Urban Design. Retrieved from http://www.elsevier.com

Cottrell, J. R., \& Cottrell, S. P. (2015). Sense-of-Place Influences on Perceived Environmental Change: Effects on Future Holiday Experiences to Saaremaa, Estonia. Scandinavian Journal of Hospitality and Tourism, 15(4), 425-446. https://doi.org/10.1080/15022250.2015.1024820

Davis, P., Huang, H.-Y., \& Liu, W.-C. (2010). Heritage, local communities and the safeguarding of "Spirit of Place" in Taiwan.

Duxbury, N., Gillette, E., \& Pepper, K. (2007). Creative City News: Exploring the cultural dimensions of sustainability. Edition 4.

English Heritage. (2009). Heritage Counts 2009 / England. Retrieved from www.englishheritage.org.uk/heritagecounts

Feilden, B. M. (2003). Conservation of historic buildings. Oxford : Architectural Press.

Ford, L. R. (1974). Historic Preservation and the Sense of Place. Growth and Change, April, 33-37.

Gosling, E., \& Williams, K. J. H. (2010). Connectedness to nature, place attachment and conservation behaviour: Testing connectedness theory among farmers. Journal of Environmental Psychology, 30(3), 298304. https://doi.org/10.1016/j.jenvp.2010.01.005

Graham, H., Mason, R., \& Newman, A. (2009). Literature Review: Historic Environment, Sense of Place, and Social Capital. Retrieved from http://www.ncl.ac.uk/sacs/icchs/ 
Graham, S., \& Healey, P. (1999). Relational concepts of space and place: Issues for planning theory and practice Relational Concepts of Space and Place: Issues for Planning Theory and Practice. European Planning Studies, 7(5), 623-646. https://doi.org/10.1080/09654319908720542

Hague, C., \& Jenkins, P. (2004). Place identity, participation and planning. In Place Identity, Participation and Planning. https://doi.org/10.4324/9780203646755

Harper, T., Yeh, A. G., \& Costa, H. (2015). Dialogues in urban and regional Planning. London: Routledge.

Hashemnezhad, H., Heidari, A. A., \& Hoseini, P. M. (2013). "Sense of place" and "place attachment": A comparative study. International Journal of Architecture and Urban Development, 3(1), 5-12.

Hawke, Stephanie K. (2011). Local residents exploring heritage in the North Pennines of England: sense of place and social sustainability. International Journal of Heritage and Sustainable Development, 1(1), 32-40. Retrieved from institute.org/volumes/2011/IJHSD_2011_V01_01_Hawke_32_40.pdf

Hawke, Stephanie Kate. (2010). Sense of Place, Engagement with Heritage and Ecomuseum Potential in the North Pennines AONB Doctor of Philosophy. Newcastle University.

Hoch, C. (2006). Emotions and planning. Planning Theory and Practice, 7(4), 367-382. https://doi.org/10.1080/14649350600984436

Hummon, D. M. (1992). Community Attachment - Local Sentiment and Sense of Place. Human Behavior and Environment - Advances in Theory and Research, 12, 253-278.

Jivén, G., \& Larkham, P. J. (2003). Sense of place, authenticity and character: A commentary. Journal of Urban Design, 8(1), 67-81. https://doi.org/10.1080/1357480032000064773

Jorgensen, B. S., \& Stedman, R. C. (2001). Sense of Place as an attitude: Lakeshore owners attitudes toward their properties. Journal of Environmental Psychology, 21(3), 233-248. https://doi.org/10.1006/jevp.2001.0226

Jorgensen, B. S., \& Stedman, R. C. (2006). A comparative analysis of predictors of sense of place dimensions: Attachment to, dependence on, and identification with lakeshore properties. Journal of Environmental Management, 79(3), 316-327. https://doi.org/10.1016/j.jenvman.2005.08.003

Kianicka, S., Buchecker, M., Hunziker, M., \& Müller-Böker, U. (2006). Locals' and tourists' sense of place: A case study of a Swiss Alpine Village. Mountain Research and Development, 26(1), 55-63.

Kolodziejski, A. L. (2014). Connecting People and Place: Sense of Place and Local Action School of Environment, Education and Development: Planning and Environmental Management (University of Manchester). Retrieved from http://documents.manchester.ac.uk/DocuInfo.aspx?

Lynch, K. (1981). A theory of good city form. Cambridge, MA.: MIT Press.

Manzo, L. C., \& Perkins, D. D. (2006). Finding common ground: The importance of place attachment to community participation and planning. Journal of Planning Literature, 20(4), 335-350. https://doi.org/10.1177/0885412205286160

Martokusumo, W., \& Zulkaidi, D. (2014). Some notes on area-based conservation: Lesson learned from Bandung. International Journal Of Built Environment and Sustainability, 2(2), 125-130.

Martokusumo, W. (2011). The notion of authenticity revisited a search for urban heritage conservation approach. Tataloka, 13(3).

Martokusumo, W. (2015). Arsitektur dan pelestarian: Menuju pengelolaan berkelanjutan bangunan dan lingkungan cagar budaya. Orasi Ilmiah Guru Besar Institut Teknologi Bandung, 25 September. Bandung: Institut Teknologi Bandung.

Martokusumo, Widjaja. (2002). Urban Heritage Conservation in Indonesia: Experiences in Bandung and Jakarta. In P. J. M. (ed. . Nas (Ed.), Indonesian Town Revisited (pp. 374-375). Germany: Lit Verlag.

Masterson, V. A., Stedman, R. C., Enqvist, J., Tengö, M., Giusti, M., Wahl, D., \& Svedin, U. (2017). The contribution of sense of place to social-ecological systems research: A review and research agenda. Ecology and Society, 22(1). https://doi.org/10.5751/ES-08872-220149

Montgomery, J. (1998). Making a city: urbanity, vitality and urban design. In Journal of Urban Design (Vol. 3). https://doi.org/10.1080/13574809808724418

Morel-Edniebrown, F. (2011). Community engagement, heritage, and rediscovering a sense of place in Northbridge, Perth Australia. International Journal of Asia Pacific Studies, 7(1), 1-25. Retrieved from http://www.northbridgehistory.wa.gov.au/uhtml/

Nagel, T. (1986). The view from nowhere. New York: Oxford.

Nanzer, B. (2004). Measuring Sense of Place: A Scale For Michigan. Administrative Theory \& Praxis, 26(3), 362382. https://doi.org/10.1080/10841806.2004.11029457 
Nasser, N. (2002). Planning for Urban Heritage Places: Reconciling Conservation, Tourism, and Sustainable Development Noha Nasser. Journal of Planning Literature, 17(4). https://doi.org/10.1177/0885412203251149

Nussbaum, M. (2003). Upheavals of thought: The intelligence of emotions. New York: Cambridge University Press.

Orbasli, A. (2000). Tourists in Historic Towns: Urban Conservation and Heritage Management. London: E \& FN Spon.

Ouf, A. M. S. (2001). Authenticity and the sense of place in urban design. Journal of Urban Design, 6(1), 73-86. https://doi.org/10.1080/13574800120032914

Poerwoningsih, D., Setyo, A., \& Wahid, A. (2016). Integrating visibility analysis in rural spatial planning. Procedia - Social and Behavioral Sciences, 227(November 2015), 838-844. https://doi.org/10.1016/j.sbspro.2016.06.153

Punter, J. (1991). Participation in the design of urban space. Landscape Design, 200, 24-27.

Puren, K., Drewes, E., \& Roos, V. (2007). An exploration of sense of place as informative for spatial planning guidelines: A case study of the Vredefort Dome World Heritage Site, South Africa. World Academy of Science, Engineering and Technology, 28(4), 42-49.

Ramkissoon, H., Weiler, B., \& Smith, L. D. G. (2012). Place attachment and pro-environmental behaviour in national parks: The development of a conceptual framework. Journal of Sustainable Tourism, 20(2), 257276. https://doi.org/10.1080/09669582.2011.602194

Raymond, C. M., Kyttä, M., \& Stedman, R. (2017). Sense of place, fast and slow: The potential contributions of affordance theory to sense of place. Frontiers in Psychology, 8(SEP). https://doi.org/10.3389/fpsyg.2017.01674

Relph, E. (1976). Place and placelessness. London: Pion.

Rodwell, D. (2003). Sustainability and the holistic approach to the conservation of historic cities. Journal of Architectural Conservation, 9(1), 58-73. https://doi.org/10.1080/13556207.2003.10785335

Scannell, L., \& Gifford, R. (2010). Defining place attachment: A tripartite organizing framework. Journal of Environmental Psychology, 30(1), 1-10. https://doi.org/10.1016/j.jenvp.2009.09.006

Shinbira, I. A. (2012). Conservation of the Urban Heritage to Conserve the Sense of Place, a Case Study Misurata City, Libya. 2nd International Conference-Workshop on Sustainable Architecture and Urban Design, 3-5. Retrieved from http://tuengr.com/ATEAS/V01/253-264.pdfhttp://TuEngr.com/

Smith, K. M. (2011). The relationship between residential satisfaction, sense of community, sense of belonging and sense of place in a Western Australian urban planned community Recommended Citation (Edith Cowan University). Retrieved from http://ro.ecu.edu.au/theses/460

Stedman, R. C. (2002). Toward a social psychology of place Predicting Behavior From Place-Based Cognitions, Attitude, and Identity. Environment and Behavior, 34(5), 561-581.

Stedman, R. C. (2003). Is It Really Just a Social Construction?: The Contribution of the Physical Environment to Sense of Place. Society \& Natural Resources: An International Journal, 18(8), 37-41. https://doi.org/10.1080/08941920390217627

Thompson, A. W., \& Prokopy, L. S. (2016). The Role of Sense of Place in Collaborative Planning. Journal of Sustainability Education, 11(February), 1-19.

Vong, L. T. N. (2013). An investigation of the influence of heritage tourism on local people's sense of place: The macau youth's experience. Journal of Heritage Tourism, 8(4), 292-302. https://doi.org/10.1080/1743873X.2013.787084

Williams, D. R. (2014). Making sense of "place": Reflections on pluralism and positionality in place research. Landscape and Urban Planning, 131, 74-82. https://doi.org/10.1016/j.landurbplan.2014.08.002

Williams, D. R., \& Stewart, S. I. (1998). A sense of place: An elusive concept that is finding a home in ecosystem management. Journal of Forestry, 96(5), 18-23.

Zed, M. (2008). Metode penelitian kepustakaan. Jakarta: Yayasan Obor Indonesia. 